\title{
Online Leakage Detection Test of High-pressure Heater at the Power Plant
}

\author{
Wang Xin-hua ${ }^{1,2^{*}}$, Jiao Yu-lin ${ }^{2}$, Niu Yong-chao ${ }^{3}$ and Yang $\mathrm{Jie}^{2}$ \\ ${ }^{1}$ Shangqiu Vocational and Technical College, Shangqiu 476000, China \\ ${ }^{2}$ Wuhan University of Technology, Wuhan 430063, China \\ ${ }^{3}$ Shangqiu, Jinpeng, Industrial Co.Ltd. Shangqiu 476000, China
}

gyxxwxh@163.com

\begin{abstract}
Variations of acoustic emission signals of leakage of the heater versus inner pressure, leakage aperture, transmission distance and liquid state in the outer pipeline were studied through experiment and analysis. By changing one of the four factors each time, leakage failure reasons were concluded. Research results would be applied into leakage detection of heater.
\end{abstract}

Keywords: acoustic emission, high-pressure heater, leakage, online detection, acoustic emission signals

\section{Introduction}

The leakage in inner pipeline of the heater is a major failure of the reheating system at the power plant. Early online detection and diagnosis of the leakage can help track and forecast its seriousness and trend, and identify the failure and its position in highpressure heaters. This cannot only prevent the escalation of the accident, but also prepare the power plant for possible repairing work, and avoid unnecessary financial loss.

The heater operates under high pressure and at high temperatures, thus requires sophisticated detection technology. In the past years, there have been a number of methods for detecting leakage, including pressure gradient method, negative pressure wave method, flow balance method, acoustic method, system identification method, neural network method, etc., [1-6]. Among all the methods, the acoustic emission detection is fundamentally different from all others because it is a dynamic nondestructive detecting technology [7-10]. The present study, through the leakage experiment of the heater, intends to firstly find out how acoustic emission signals of leakage of the heater change with the pressure of the inner pipeline and leakage aperture, and secondly explore how the changing state of the liquid medium in the heater influences the amplitude and frequency of acoustic emission signals of leakage. The experiment consists of the following five parts. Firstly, the detection method of leakage signals of heater is explored and a plan for the detection technology of leakage signals is developed; secondly, features of acoustic emission signals are studied; thirdly, the quantitative relationship between the features of leakage and leakage condition is examined by experiment; fourthly, the propagation and attenuation features of the leakage acoustic 
emission signals are explored by experiment; finally, the technology for the localization of leakage spot is studied..

\section{Online Detection System Design}

Acoustic emission detection system and device of pipeline leakage consists of two parts, one is online detection system, and the other is simulation system.

(1) Online detection system of acoustic emission leakage

Hardware included sensor, pre-amplifier, signal acquisition card, device and data processing and analysis system. The signal acquisition card was the AEDSP2 32 /16 made in U.S. The sensor was the single-ended broadband R15, produced by PAC, with the band ranging from $50 \mathrm{kHz} \sim 1 \mathrm{MH}$. The pass-band fluctuation was smaller than $30 \mathrm{~d}$ and its sensitivity was $120 \mathrm{db}$. To make the sensor the pipeline fit, coupling agent was smeared on the surface of the sensor and a magnetic installation seat was used to ensure the tightness.

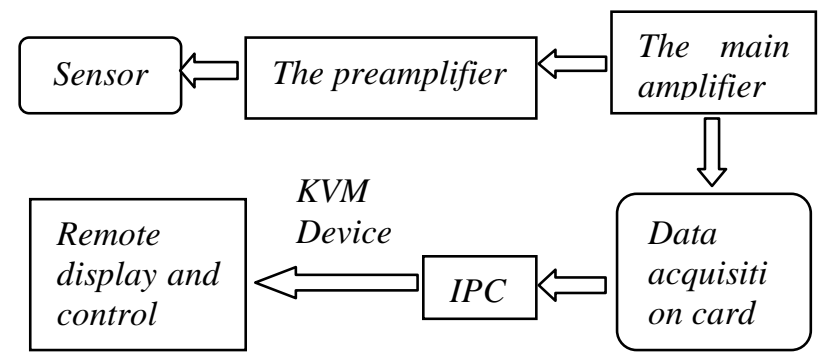

Figure 1. Online Detection System of Acoustic Emission Leakage

Yet, it is still impossible to directly detect the initial acoustic emission signals from the source. So, analyzing acoustic emission signals collected by sensors is the most effective way to obtain initial acoustic emission signals.

(2) Simulation system of heater leakage

The structure of the heater and its working principles are quite complex. To facilitate the research, only heat transfer and leakage were simulated. Heat transfer occurred between the input water and the stream. For leakage simulation, the pressure of the input water and that of the stream were adjusted to cause pressure difference in order to crack the pipeline. Acoustic emission sensor, preamplifier and acoustic emission detector were connected to detect and analyze acoustic emission signals of leakage. Simulation system of heater leakage is shown in Figure 2. 


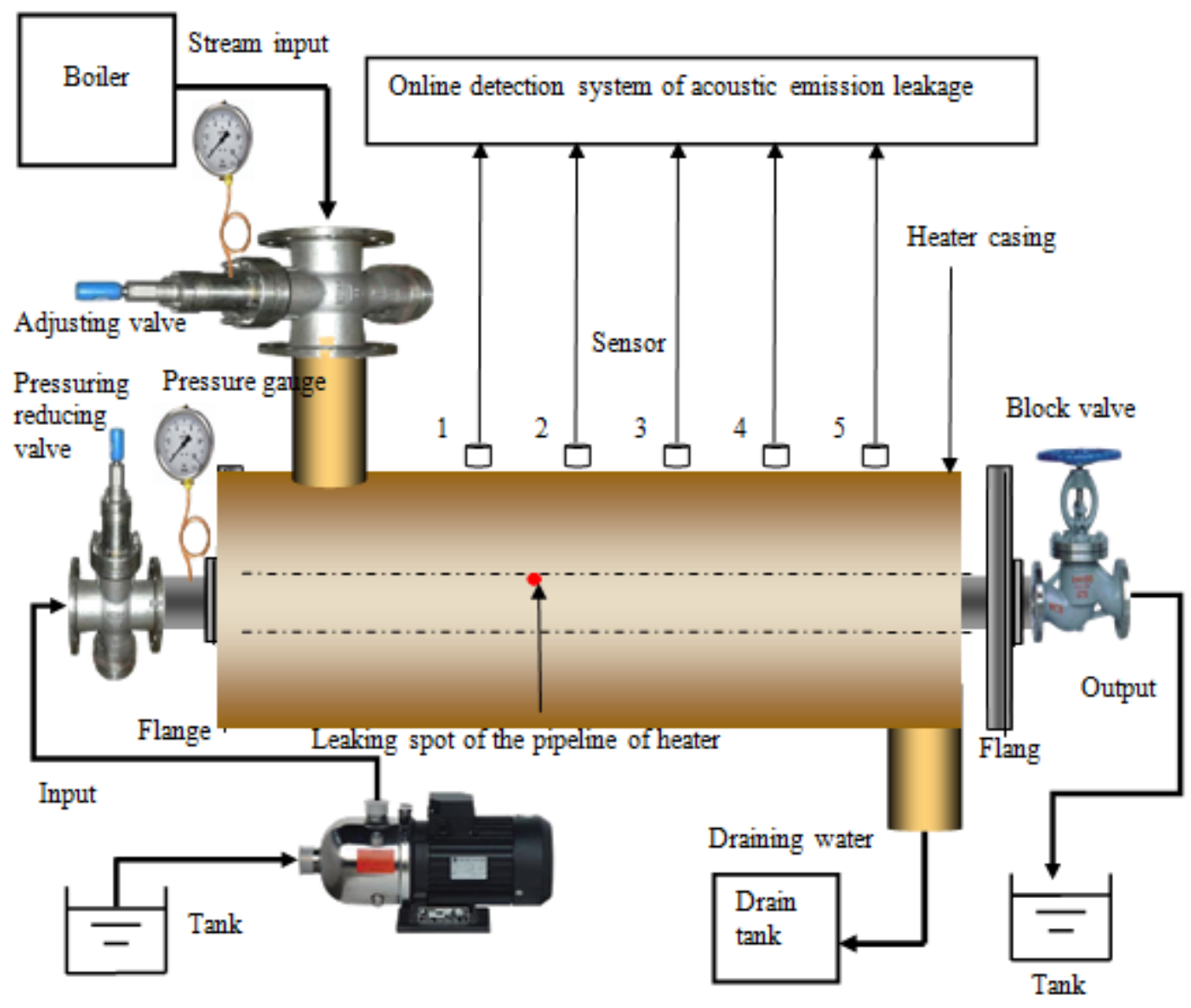

Figure 2. Simulation System of Pipeline Leakage

\section{Calculation Model}

(1)Thermodynamic calculation

The high-pressure heater is a kind of heat exchanger with pipelines providing its heat transfer surface. The main forms of heat transfer are convection, heat conduction, etc. where hot liquid and cold liquid are separated by the pipe wall and heat transfers from the former to the latter as the hot liquid flows through the pipe. The cold liquid of the high-pressure heater is water which flows in the pipeline while the hot liquid is steam, i.e., the steam extracted from turbine, which flows outside the pipeline. The highpressure heater has several heat transfer section including superheat steam cooling section, saturated steam condensation section, and liquid water cooling section. In these sections, the hot liquid exists in different forms involving superheat steam, saturated steam and liquid water [11-13].

In calculating heat transfer in the simple condensation section of the high-pressure heater, the transferred heat $\mathrm{Q}$ is calculated by equation (1):

$$
Q=G\left(h_{2}-h_{1}\right) \times 10^{3}=D\left(H_{1}-H_{2}\right) \eta \times 10^{3}
$$

(1)

In (1): 
$Q$ is transferred heat $(\mathrm{W}) ; G$ is flow rate of feedwater $(\mathrm{kg} / \mathrm{s}) ; h_{1}$ and $h_{2}$ are the enthalpy of the feedwater inlet and outlet respectively $(\mathrm{kJ} / \mathrm{kg}) ; D$ is flow rate of steam $(\mathrm{kg} / \mathrm{s}) ; H_{1}$ and $\mathrm{H}_{2}$ are the enthalpy of the steam inlet and the feedwater outlet respectively ( $\mathrm{kJ} / \mathrm{kg}$ ); $\eta$ is the heat radiation coefficient in consideration of the radiation from the heater's outside surface to the atmosphere. It is multiplied by the transferred heat of the pipe wall next to the steam of hot liquid, which makes $0.97^{\sim} 0.99$ from which the present study selects 0.97 [14$15]$.

The detailed data of thermodynamic calculation is shown in Table 1.

\section{Table 1. Thermodynamic Calculation Table of the Simulation Test Bench of the Heater}

\begin{tabular}{|c|c|c|c|c|c|}
\hline Name & $\begin{array}{c}\text { Symb } \\
\text { ol }\end{array}$ & Unit & Formula & Value & Notes \\
\hline $\begin{array}{l}\text { Diameter of } \\
\text { pipelines }\end{array}$ & $d_{o} / d_{i}$ & $\mathrm{~mm} / \mathrm{mm}$ & Selection & $22 / 18$ & \\
\hline $\begin{array}{l}\text { Feedwater } \\
\text { pressure }\end{array}$ & $p_{w}$ & $M P a$ & Preset pressure & 0.7 & \\
\hline $\begin{array}{c}\text { Temperature } \\
\text { of feedwater } \\
\text { inlet }\end{array}$ & $t_{1}$ & ${ }^{\circ} \mathrm{C}$ & Preset temperature & 25 & \\
\hline $\begin{array}{l}\text { Enthalpy of } \\
\text { feedwater inlet }\end{array}$ & $h_{1}$ & $\mathrm{~kJ} / \mathrm{kg}$ & $\begin{array}{l}\text { Obtained from checking } \\
\text { records according to } \\
\text { feedwater temperature } \\
\text { and pressure } \\
\end{array}$ & 105.48 & \\
\hline $\begin{array}{c}\text { Feedwater } \\
\text { speed }\end{array}$ & $V$ & $m / s$ & Selection & 15 & $5 \sim 20$ \\
\hline $\begin{array}{l}\text { Flow rate of } \\
\text { feedwater }\end{array}$ & $G$ & $\mathrm{~kg} / \mathrm{s}$ & $G=\rho V A=\frac{1}{4} \rho V \pi d_{i}^{2}$ & 3.8151 & $\begin{array}{c}\text { The diameter } \\
\text { of the } \\
\text { pipeline is } \\
18 \mathrm{~mm} .\end{array}$ \\
\hline $\begin{array}{c}\text { Flow rate of } \\
\text { steam }\end{array}$ & $D$ & $\mathrm{~kg} / \mathrm{s}$ & Original data & 0.028 & \\
\hline $\begin{array}{c}\text { Steam } \\
\text { temperature }\end{array}$ & $T_{1}^{\prime}$ & ${ }^{\circ} \mathrm{C}$ & Original data & 170 & $169 \sim 172$ \\
\hline $\begin{array}{c}\text { Steam } \\
\text { pressure }\end{array}$ & $p_{1}$ & $M P a$ & Original data & 0.7 & \\
\hline $\begin{array}{l}\text { Enthalpy of } \\
\text { steam inlet }\end{array}$ & $H_{1}$ & $\mathrm{~kJ} / \mathrm{kg}$ & $\begin{array}{l}\text { Obtained from checking } \\
\text { records according to } \\
\text { steam temperature and } \\
\text { pressure }\end{array}$ & 2775.36 & \\
\hline $\begin{array}{l}\text { Steam } \\
\text { pressure after } \\
\text { opening the } \\
\text { throttle }\end{array}$ & $p_{1}$ & $M P a$ & Preset pressure & 0.2 & \\
\hline Steam & $T_{1}$ & ${ }^{\circ} \mathrm{C}$ & Enthalpy unchanged & 153.04 & \\
\hline
\end{tabular}




\begin{tabular}{|c|c|c|c|c|c|}
\hline $\begin{array}{l}\text { temperature } \\
\text { after opening } \\
\text { the throttle }\end{array}$ & & & $\begin{array}{l}\text { despite opening the } \\
\text { throttle. Obtained from } \\
\text { checking records } \\
\text { according to the } \\
\text { enthalpy }\end{array}$ & & \\
\hline $\begin{array}{l}\text { Latent heat } \\
\text { from } \\
\text { vaporization }\end{array}$ & & $\mathrm{kJ} / \mathrm{kg}$ & $H_{g}-H_{l}$ & 2104.13 & $\begin{array}{c}\text { Steam } \\
\text { temperature } \\
\text { is } 153.04^{\circ} \mathrm{C}\end{array}$ \\
\hline $\begin{array}{c}\text { Enthalpy of } \\
\text { draining water } \\
\text { outlet } \\
\end{array}$ & $\mathrm{H}_{2}$ & $\mathrm{~kJ} / \mathrm{kg}$ & $H_{1}-H_{2}=H_{g}-H_{l}$ & 671.23 & \\
\hline $\begin{array}{l}\text { Temperature } \\
\text { of draining } \\
\text { water }\end{array}$ & $T_{2}$ & ${ }^{\circ} \mathrm{C}$ & $\begin{array}{l}\text { Obtained from checking } \\
\text { enthalpy records } \\
\text { according to } H_{2} \text { and } p_{1}\end{array}$ & 120.21 & \\
\hline $\begin{array}{c}\text { Enthalpy of } \\
\text { feedwater } \\
\text { outlet }\end{array}$ & $h_{2}$ & $k J / k g$ & $h_{2}=h_{1}+\frac{Q}{G \times 10^{3}}$ & 114.65 & \\
\hline $\begin{array}{c}\text { Temperature } \\
\text { of feedwater } \\
\text { outlet }\end{array}$ & $t_{2}$ & ${ }^{\circ} \mathrm{C}$ & $\begin{array}{l}\text { Obtained from checking } \\
\text { enthalpy records } \\
\text { according to } h_{2} \text { and } p_{w}\end{array}$ & 27.19 & \\
\hline $\begin{array}{c}\text { Average } \\
\text { temperature of } \\
\text { feedwater }\end{array}$ & $t_{f}$ & ${ }^{\circ} \mathrm{C}$ & $t_{f}=\frac{t_{1}+t_{2}}{2}$ & 26.095 & \\
\hline $\begin{array}{c}\text { Average } \\
\text { temperature } \\
\text { difference of } \\
\text { logarithm }\end{array}$ & $\Delta t_{m}$ & ${ }^{\circ} \mathrm{C}$ & $\Delta t_{m}=\frac{\Delta t_{\max }-\Delta t_{\min }[24]}{\ln \frac{\Delta t_{\max }}{\Delta t_{\min }}}$ & 109.599 & $\begin{array}{l}\Delta t_{\max }=T_{2}-t_{2} \\
\Delta t_{\text {min }}=T_{1}-t_{1}\end{array}$ \\
\hline $\begin{array}{l}\text { Saturation } \\
\text { temperature } \\
\text { and steam }\end{array}$ & $T_{s}$ & ${ }^{\circ} \mathrm{C}$ & & 120.21 & $\begin{array}{l}\text { Steam } \\
\text { pressure is } \\
0.2 M P_{a}\end{array}$ \\
\hline $\begin{array}{c}\text { Temperature } \\
\text { of the steam } \\
\text { side wall } \\
\end{array}$ & $t_{w}$ & ${ }^{\circ} \mathrm{C}$ & $\mathrm{t}_{\mathrm{w}}=\mathrm{T}_{\mathrm{s}}-0.4 \Delta \mathrm{t}_{\mathrm{m}}$ & 76.371 & \\
\hline $\begin{array}{c}\text { Average } \\
\text { temperature of } \\
\text { steam liquid } \\
\text { membrane }\end{array}$ & $t_{M}$ & ${ }^{\circ} \mathrm{C}$ & $t_{M}=\frac{1}{2}\left(T_{s}+t_{w}\right)$ & 98.291 & \\
\hline Coefficient & $B$ & & $\begin{array}{l}\text { Select from table } 5-1 \text { in } \\
\text { literature [1] }\end{array}$ & 2188.892 & \\
\hline $\begin{array}{l}\text { Heat transfer } \\
\text { coefficient of } \\
\text { steam to the } \\
\text { pipe wall }\end{array}$ & $\alpha_{1}$ & & $\begin{array}{l}\alpha_{1} \\
=0.5894 B \sqrt[4]{\frac{r}{n d_{0}\left(T_{s}-t_{w}\right)}}\end{array}$ & 8827.735 & \\
\hline
\end{tabular}




\begin{tabular}{|c|c|c|c|c|c|}
\hline $\begin{array}{c}\text { Kinematic } \\
\text { viscosity of } \\
\text { water inside } \\
\text { pipelines }\end{array}$ & $v$ & $m^{2} / s$ & $\begin{array}{l}\text { Obtained from checking } \\
\text { records according } \\
\text { to } t_{f} \text { and } p_{w}\end{array}$ & $0.8708 \times 10$ & \\
\hline $\begin{array}{l}\text { Reynolds } \\
\text { number of } \\
\text { flow inside } \\
\text { pipelines }\end{array}$ & $\mathrm{R}_{\mathrm{e}}$ & & $\mathrm{R}_{\mathrm{e}}=\frac{d_{i} w}{v}$ & $3.101 \times 10^{5}$ & \\
\hline $\begin{array}{l}\text { Thermal } \\
\text { conductivity } \\
\text { of water inside } \\
\text { pipelines }\end{array}$ & $\lambda$ & $W /\left(m^{2} \cdot{ }^{\circ} C\right)$ & $\begin{array}{c}\text { Obtained from checking } \\
\text { records according to } \\
\text { literature [1] based on } \\
t_{f}\end{array}$ & $61.04 \times 10^{-2}$ & \\
\hline $\begin{array}{l}\text { Prandtl } \\
\text { number }\end{array}$ & $\mathrm{P}_{\mathrm{r}}$ & & $\begin{array}{l}\text { Obtained from checking } \\
\text { records }\end{array}$ & 5.9555 & \\
\hline $\begin{array}{l}\text { Individual heat } \\
\text { transfer } \\
\text { coefficient of } \\
\text { the pipe wall } \\
\text { to water }\end{array}$ & $\alpha_{2}$ & & $\alpha_{2}=0.023 \frac{\lambda}{d_{i}} \mathrm{R}_{e}^{0.8} \mathrm{P}_{r}^{0.4}$ & 39375.18 & \\
\hline $\begin{array}{c}\text { Thermal } \\
\text { conductivity } \\
\text { of the pipe } \\
\text { wall }\end{array}$ & $\lambda$ & $W /\left(m^{2} \cdot{ }^{\circ} C\right)$ & $\begin{array}{c}\text { Select from table 5-2 in } \\
\text { literature [3] }\end{array}$ & 50.7 & \\
\hline $\begin{array}{l}\text { Overall-heat- } \\
\text { transfer } \\
\text { coefficient }\end{array}$ & $k$ & & $\begin{array}{l}k= \\
\frac{1}{\frac{1}{\alpha_{1}}+\frac{\delta}{\lambda}+\frac{1}{\alpha_{2}}\left(\frac{d_{0}}{d_{i}}\right)+R\left(\frac{d_{0}}{d_{i}}\right)}\end{array}$ & 5441.585 & $\begin{array}{l}\mathrm{R} \text { is fouling } \\
\text { resistance- } \\
\text { Negligible }\end{array}$ \\
\hline $\begin{array}{l}\text { Length of the } \\
\text { heat exchange } \\
\text { tube }\end{array}$ & $l$ & $m$ & $l=\frac{Q}{k \pi d_{0} \Delta t_{m}}$ & 1.39 & \\
\hline
\end{tabular}

(1) Strength test

Equation (2) is used to test pipeline strengthen:

$P=2 s R / D$

In (2), $\mathrm{P}$ is test pressure (MPa); $\mathrm{s}$ is nominal wall thickness of steel pipes (mm); D is nominal outside diameter of the pipes; $\mathrm{R}$ is permissible stress which is set as $60 \%$ of the yield point (MPa).

For heat exchange tube:

$$
\mathrm{P}=2 \mathrm{sR} / \mathrm{D}=\frac{2 \times 2 \mathrm{~mm} \times 245 \mathrm{MPa} \times 0.6}{22 \mathrm{~mm}}=44.55 \mathrm{MPa}<0.7 \mathrm{MPa}
$$


For carbon steel No. 20, R=245MPa. The result meets the requirement for the strength.

For the outside shell:

$$
\mathrm{P}=2 \mathrm{sR} / \mathrm{D}=\frac{2 \times 7 \mathrm{~mm} \times 245 \mathrm{MPa} \times 0.6}{219 \mathrm{~mm}}=9.39 \mathrm{MPa}<0.2 \mathrm{MPa}
$$

The result meets the requirement.

Strength test of the leaking spot

Many parts of the machine have holes, rounded corners and grooves like threads necessary for their structure and application. If exerted external force, the area near these holes, rounded corners and grooves will face growing stress which produces stress concentration. It can cause cracks in the parts and even render them completely broken [16]. In the present experiment, the leaking spot is very likely to face stress concentration and it cannot be eliminated. Therefore, for safety reasons, it is necessary to test the strength of the leaking spot.

The formula used to calculate the stress of the leaking spot is:

$$
\sigma_{\theta}=\frac{\Delta p d}{\Delta \delta \times 2}
$$

In (5), $\Delta P$ is the internal-external pressure difference (MPa); $d$ is the average diameter (mm); and $\Delta \delta$ is the thickness of the pipeline ( $\mathrm{mm})$.

The calculation results in the equation:

$\sigma_{\theta}=\frac{\Delta p d}{\Delta \delta \times 2}=\frac{(0.7 \mathrm{MPa}-0.2 \mathrm{MPa}) \times 19.5 \mathrm{~mm}}{4.5 \mathrm{~mm} \times 2}=1.083 \mathrm{MPa}$. The corrected stress is

$\sigma_{\theta}^{*}=\sigma_{\theta}(3 \sim 3.3)=3.1 \times \sigma_{\theta}=3.36 \mathrm{MPa}$. This paper takes 3.1 as the correction coefficient.

The highest stress of the leaking spot is:

$$
\begin{aligned}
& \sigma_{\max }=\frac{\sigma_{\theta}^{*}-\sigma_{r}}{2} \\
& {[\tau]=\frac{\sigma}{2}=\frac{235 M P a}{2}=117.5}
\end{aligned}
$$

In the equation above, $\sigma=235 \mathrm{MPa}$ where $\sigma$ is permissible stress of carbon steel No. Q235.

If $\sigma_{\max } \leq[\tau]$, the requirement is satisfied.

In the present experiment, the internal and external pressures of the leaking spot are $\sigma_{r \max }=0.7 M P a$ and $\sigma_{r \min }=0.2 M P a$ respectively.

When $\sigma_{r \max }=0.7 M P a$,

$$
\sigma_{\max }=\frac{\sigma_{\theta}^{*}-\sigma_{r}}{2}=\frac{3.36 M P a-0.7 M P a}{2}=1.45 M P a \leq[\tau]
$$

When $\sigma_{r \text { min }}=0.2 M P a$,

$$
\sigma_{\max }=\frac{\sigma_{\theta}^{*}-\sigma_{r}}{2}=\frac{3.36 \mathrm{MPa}-0.2 \mathrm{MPa}}{2}=1.58 \mathrm{MPa} \leq[\tau]
$$

Therefore, the strength of the leaking spot meets the requirement. 


\section{Data analysis}

(1) Variation of Amplitude and Frequency Spectrum of Acoustic Emission Signals of Leakage Versus Pressure

(1) Acoustic emission signals of leakage were analyzed with the frequency-spectrum analyzing module in the online detection system. Figure 3 shows the waveform and the frequency spectrum of acoustic emission signals of leakage when the internal pressure is $0.45 \mathrm{MPa}$ and $0.25 \mathrm{MPa}$.

1) When the pressure is $0.25 \mathrm{MPa}$, leakage signals amplitude is about $3 \mathrm{~V}$. When the pressure is $0.45 \mathrm{MPa}$, the amplitude increases to $5 \mathrm{~V}$. The conclusion reached is that under the same leakage aperture, the amplitude of acoustic emission signals of leakage continues to increase versus the internal pressure. The frequency of acoustic emission signals of leakage mainly concentrates between $0 \sim 300 \mathrm{kHz}$.
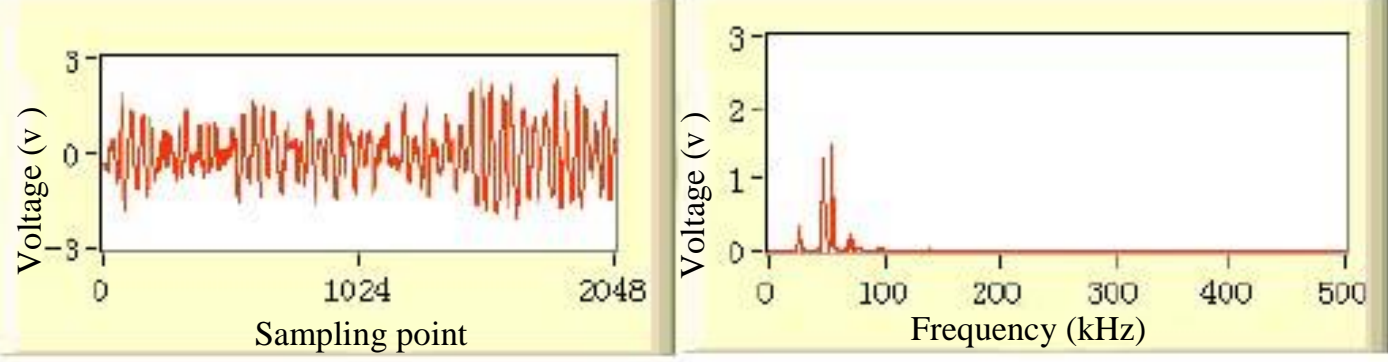

(a) The Internal Pressure is $0.25 \mathrm{Mpa}$
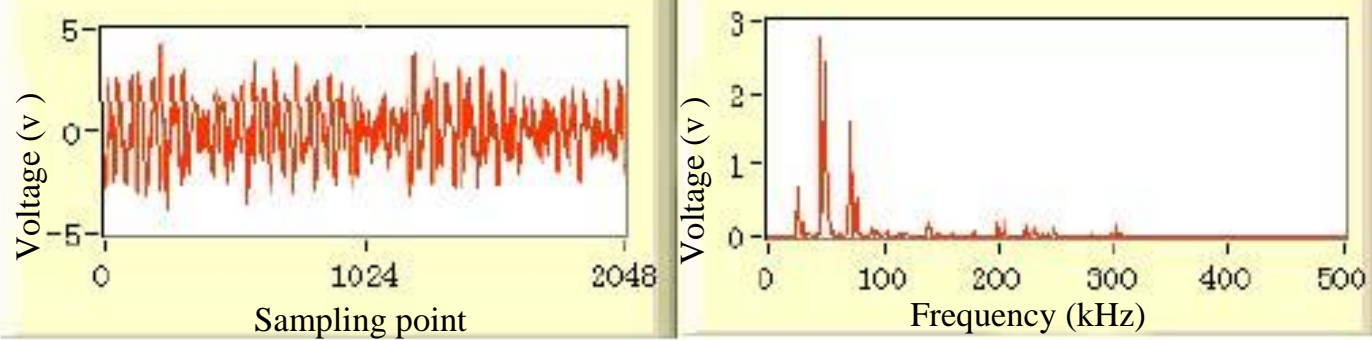

(b) The Internal Pressure is $0.45 \mathrm{Mpa}$

Figure 3. Waveform and Frequency Spectrum of Acoustic Emission Signals of Leakage under Different Pressures

(2) Acoustic emission signals of leakage were analyzed with the wave composition module in the online detection system and the percentage of energy at each frequency was computed. Figure 4 shows the energy percentage at each frequency. 


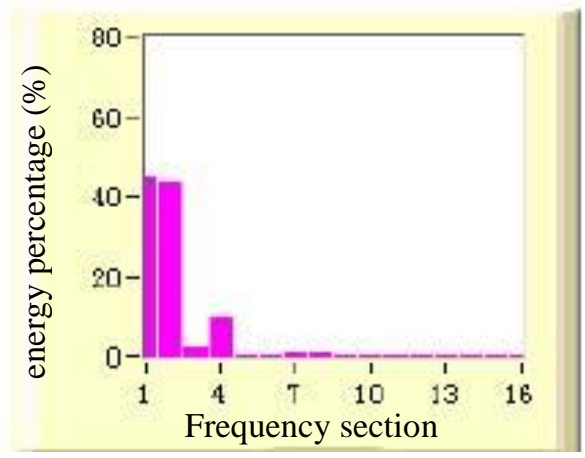

(a) The internal pressure is $0.25 \mathrm{Mpa}$

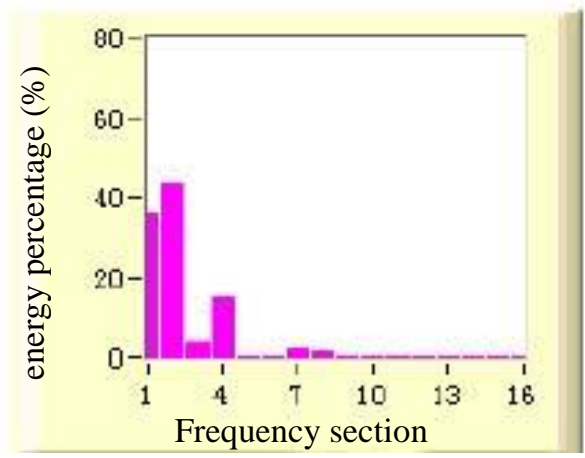

(b) The internal pressure is $0.45 \mathrm{Mpa}$

Figure 4. Energy Percentage at Each Frequency

When the internal pressure is increased from $0.25 \mathrm{MPa}$ to $0.45 \mathrm{MPa}$, energy at each frequency has no significant change. This is because during the leakage, the internal pressure exceeds critical pressure, which blocks the leakage. If the leakage aperture remains unchanged, peak frequency of the leakage noises would not change.

(3) At $1 \mathrm{~mm}$ of leaking spot, variations of acoustic emission signals of leakage of the pipeline and acoustic emission signals of leakage of the jacketed piping versus pressure were compared, as shown in Figure 5:

f leakage of the jacketed piping versus pressure were compared, as shown in Figure 5:

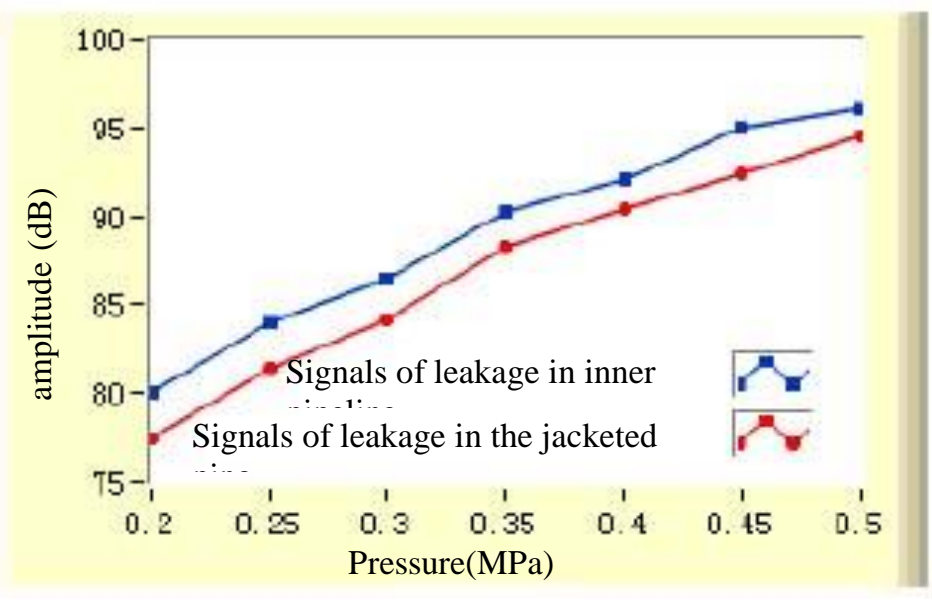

\section{Figure 5. Acoustic Emission Signals of Leakage in Inner Pipeline and the Jacketed Piping Versus Pressure}

As the pressure is increased, both curves continue to rise, indicating that the signals are growing stronger. The amplitude of acoustic emission signals of leakage of the pipeline is higher than that of the jacketed piping. This is more obvious under high pressure than under low pressure. The explanation is that when the pressure increases, the movement of gas is faster, creating louder voice and resulting in higher amplitude. When the leakage occurred in the pipeline, as the sensor is very close to the leaking spot, signals collected by the sensor can be seen as the source signal. When the leakage occurred in the jacketed piping, signals collected by the sensor are noises transmitted from the outer pipeline. When the signals touch 
the outer pipeline, the energy would be reduced. So the amplitude of signals of leakage in the jacketed piping is a little lower than those in the pipeline.

(2) Variation of Waveform and Frequency Spectrum of Acoustic Emission Signals of Leakage Versus Leakage Aperture

Figure 6 shows waveform and frequency spectrum of acoustic emission signals of leakage under different leakage apertures when the internal pressure is $0.3 \mathrm{Mpa}$. It can be seen that:

$\Phi$ Waveforms were compared. It is found that signals present different amplitudes under different apertures. A big leakage aperture corresponds to big amplitude.

2 The frequency spectrums at different leaking spots are compared. Leakage aperture has great influence on the frequency energy of acoustic emission signals of leakage but little influence on the frequency distribution. The frequency of signals mainly concentrates between $0 \sim 300 \mathrm{kHz}$.
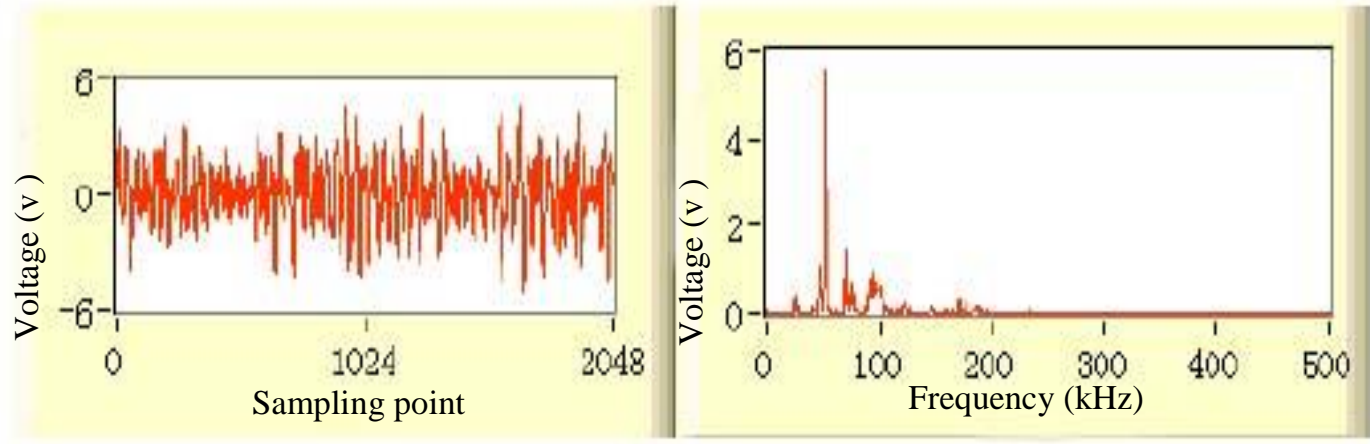

(a) $1 \mathrm{~mm}$ leaking spot
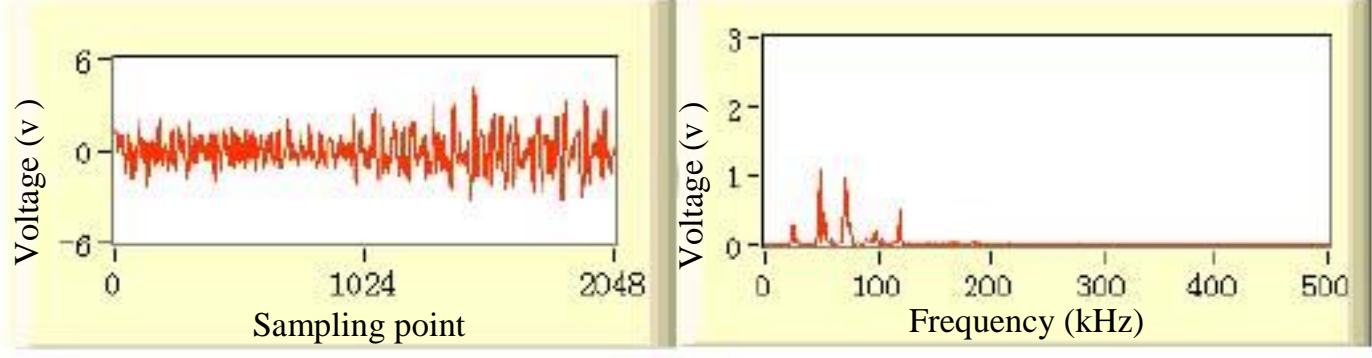

(b) $3 \mathrm{~mm}$ leaking spot

\section{Figure 6. Waveform and Frequency Spectrum of Acoustic Emission Signals of Leakage at Different Leakage Spots}

\section{(3) Variation of Leakage Signal Amplitude Versus Liquid Media}

Heater cannot only be used at the power plan, but also serve as chemical reactor in the petrochemical engineering devices. A heater consists of inner pipeline and outer pipeline. The transmission media in the inner pipeline of the heater is water or raw materials while that in the outer pipeline, vapor, hot water, refrigerant or PCB carrier. 


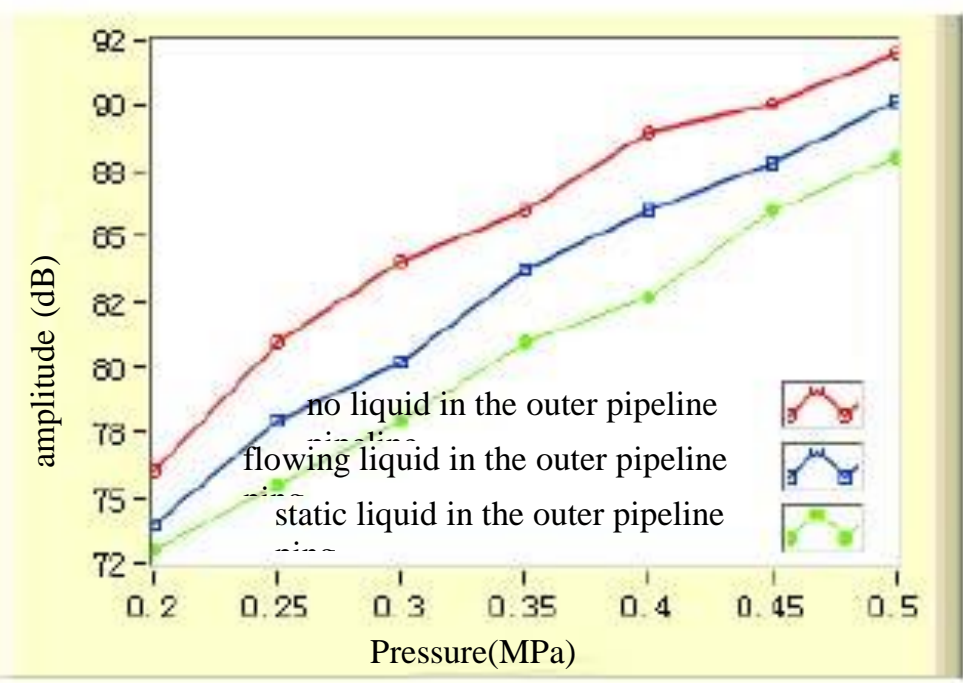

Figure 7. Leakage Signal Amplitude Versus Internal Pressure

From Figure 7, it can be seen that when the internal pressure increases, the signal energy also increases. The amplitude of acoustic emission signals of leakage is the largest when there is no liquid in the outer pipeline and the smallest when there are static liquid in the outer pipeline. This indicates that when leakage occurred in the inner pipeline, liquid in the outer pipeline would hinder the transmission of static liquid in the outer pipeline. The amplitude of acoustic emission signals of leakage is higher when there is flowing liquid in the outer pipeline than under the condition of static liquid, which is because flowing liquid also produces noises that harass the detection of acoustic emission signals of leakage.

\section{(4) Variation of Leakage Signal Amplitude Versus Transmission Distance}

Figure 8 shows the variation of leakage signal amplitude versus transmission distance when the internal pressure is $0.25 \mathrm{MPa}$.

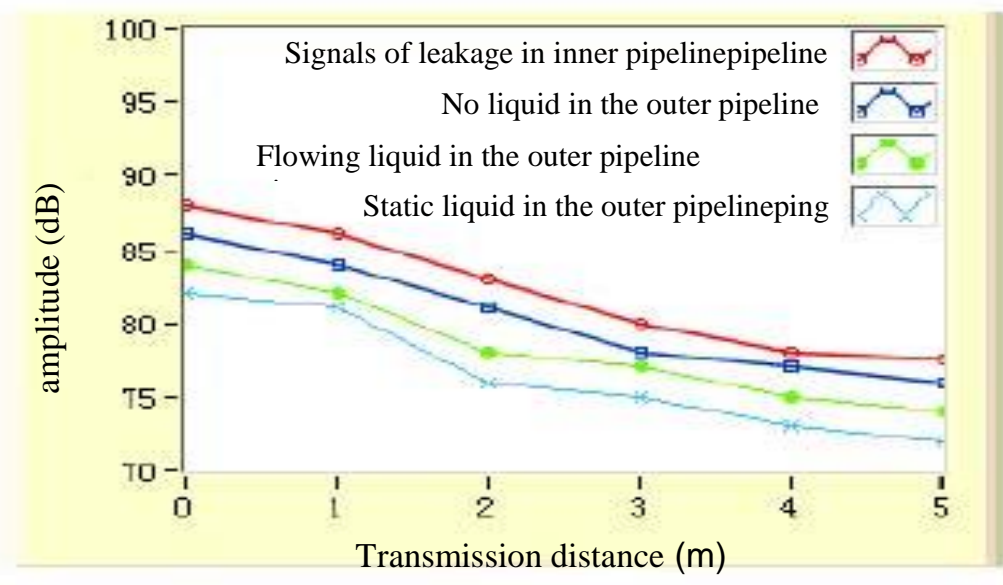

Figure 8. Leakage Signal Amplitude Versus Transmission Distance

It can be concluded that as the transmission distance increases, the amplitude of acoustic emission signals of leakage gradually reduces. The amplitude of acoustic emission signals 
under the condition of static liquid reduces the most significant, which further proves that the liquid in the outer pipeline interferes with the transmission of acoustic emission signals.

\section{Conclusion}

Variations of acoustic emission signals of leakage of the heater versus inner pressure, leakage aperture, transmission distance and liquid state in the outer pipeline were studied. By changing one of the four factors each time, leakage failure reasons were concluded:

(1) The amplitude and energy of acoustic emission signals of leakage increased versus pressure. From the frequency spectrum of acoustic emission signals, the frequency is mainly concentrated between $0 \sim 300 \mathrm{kHz}$. Energy at each frequency has no significant change. This is because during the leakage, the internal pressure exceeds critical pressure, which blocks the leakage. If the leakage aperture remains unchanged, peak frequency of the leakage noises would not change.

(2) As the pressure is increased, both curves continue to rise, indicating that the signals are growing stronger. The amplitude of acoustic emission signals of leakage of the pipeline is higher than that of the jacketed piping. This is more obvious under high pressure than under low pressure. The explanation is that when the pressure increases, the movement of gas is faster, creating louder voice and resulting in higher amplitude. When the leakage occurred in the pipeline, as the sensor is very close to the leaking spot, signals collected by the sensor can be seen as the source signal. When the leakage occurred in the jacketed piping, signals collected by the sensor are noises transmitted from the outer pipeline. When the signals touch the outer pipeline, the energy would be reduced. So the amplitude of signals of leakage in the jacketed piping is a little lower than those in the pipeline.

(3) Under different leakage apertures, the amplitudes of acoustic emission signals are distinct. A big leakage aperture corresponds to big amplitude. Leakage aperture has great influence on the frequency energy of acoustic emission signals of leakage but little influence on the frequency distribution. The frequency of signals mainly concentrates between $0 \sim 300 \mathrm{kHz}$.

(4) The amplitude of acoustic emission signals of leakage is the largest when there is no liquid in the outer pipeline and the smallest when there are static liquid in the outer pipeline. This indicates that when leakage occurred in the inner pipeline, liquid in the outer pipeline would hinder the transmission of static liquid in the outer pipeline. The amplitude of acoustic emission signals of leakage is higher when there is flowing liquid in the outer pipeline than under the condition of static liquid, which is because flowing liquid also produces noises that harass the detection of acoustic emission signals of leakage.

(5) As the transmission distance increases, the amplitude of acoustic emission signals of leakage gradually reduces. The amplitude of acoustic emission signals under the condition of static liquid reduces the most significant, which further proves that the liquid in the outer pipeline interferes with the transmission of acoustic emission signals.

\section{Acknowledgements}

Foundation item: Nature Science Foundation of Henan Science and Technology Bureau (141008) (141080); Major science and technology research plan project in Henan province (142102110028); 


\section{References}

[1] G. Heo and S. K. Lee, "Internal leakage detection for feedwater haters in power plants using neural networks", Expert Systems with Applications, vol. 39, Issue 5, (2012) April, pp. 5078-5086.

[2] M. G. Reddy, "INFLUENCE OF THERMAL RADIATION ON NATURAL CONVECTION BOUNDARY LAYER FLOW OF A NANOFLUID PAST A VERTICAL PLATE WITH UNIFORM HEAT FLUX”, International Journal of Heat and Technology, vol. 32, no. 1, 2, (2014), pp. 1-7.

[3] M. J. Eaton, R. Pullin and K. M. Holford, "Acoustic emission source location in composite materials using Delta T Mapping", Composites Part A: Applied Science and Manufacturing, vol. 43, Issue 6, (2012) June, pp. 856-863.

[4] S. Hao, J. Shuguang, W. Lanyun and W. Zhengyan, "King factor of the strata overlying the gob and a threedimensional numerical simulation of the air leakage flow field", Mining Science and Technology (China), vol. 21, Issue 2, (2011) March, pp. 261-266.

[5] S. Ghosh, D. Mukhopadhyay and S. K. Saha, "An experimental analysis of subcooled leakage flow through slits from high pressure high temperature pipelines”, International Journal of Pressure Vessels and Piping, vol. 88, Issues 8-9, (2011) August-September, pp. 281-289.

[6] D. A. Ghertner and M. Fripp, "Ding away damage: Quantifying environmental leakage through consumptionbased, life-cycle analysis”, Ecological Economics, vol. 63, Issues 2-3, (2007) August 1, pp. 563-577.

[7] W. M. Chambers, N. J. Mc and C. Mortensen, "Toperative leakage and abscess formation after colorectal surgery”, Best Practice \& Research Clinical Gastroenterology, vol. 18, Issue 5, (2004) October, pp. 865-880.

[8] C.-M. Keum, J.-H. Bae, M.-H. Kim, W. Choi and S.-D. Lee, "Ution-processed low leakage organic fieldeffect transistors with self-pattern registration based on patterned dielectric barrier", Organic Electronics, vol. 13, Issue 5, (2012) May, pp. 778-783.

[9] H. Román-Flores, A. Flores-Franulič and Y. Chalco-Cano, "fuzzy integrals", Applied Mathematics and Computation, vol. 204, Issue 1, (2008) October 1, pp. 178-183.

[10] C. Lei and P. Zou, "Application of neural network in heating network leakage fault diagnosis", Journal of Southeast University, vol. 26, no. 2, pp. 173-176.

[11] D. S. Reddy, G. S. Sarma and K. Govardhan, "NUMERICAL STUDY OF MHD, THERMAL RADIATION FREE COVECTION HEAT AND MASS TRANSFER FROM VERTICAL SURFACES IN POROUS MEDIA CONSIDERING SORET AND DUFOUR EFFECTS", International Journal of Heat and Technology, vol. 32, no. 1 \& 2, (2014), pp. 179-184.

[12] S. E. Rafiee, M. Rahimi and N. Pourmahmoud, "THREE-DIMENSIONAL NUMERICAL INVESTIGATION ON A COMMERCIAL VORTEX TUBE BASED ON AN EXPERIMENTAL MODEL PART I: OPTIMIZATION OF THE WORKING TUBE RADIUS”, International Journal of Heat and Technology, vol. 31, no. 1, (2013), pp. 49-56.

[13] D. H. Zhou, X. He, Z. Wang, G.-P. Liu and Y. D. Ji, "Leakage Fault Diagnosis for an Internet-Based ThreeTank System: An Experimental Study”, IEEE Transactions on Control Systems Technology, (2011) June 13.

[14] E. Tuncay and Y. Obara, "Comparison of stresses obtained from Acoustic emission and Compact ConicalEnded Borehole Overcoring techniques and an evaluation of the Kaiser Effect level", Bulletin of Engineering Geology and the Environment, vol. 71, no. 2, (2012), pp. 367-377.

[15] S. E. Rafiee, M. Rahimi and N. Pourmahmoud, "THREE-DIMENSIONAL NUMERICAL INVESTIGATION ON A COMMERCIAL VORTEX TUBE BASED ON AN EXPERIMENTAL MODEL PART I: OPTIMIZATION OF THE WORKING TUBE RADIUS", International Journal of Heat and Technology, vol. 31, no. 1, (2013), pp. 49-56.

[16] Q. Dai, K. Ng, J. Zhou, E. L. Kreiger and T. M. Ahlborn, "Damage investigation of single-edge notched beam tests with normal strength concrete and ultra-high performance concrete specimens using acoustic emission techniques", Construction and Building Materials, vol. 31, (2012) June, pp. 231-242. 
International Journal of Smart Home

Vol. 9, No. 3 (2015) 